\title{
Sleep Disorders in Patients With Breast Cancer Prior to a Course of Radiotherapy - Prevalence and Risk Factors
}

\author{
DIRK RADES ${ }^{1}$, CARLOS A. NARVAEZ $^{1}$, LIESA DZIGGEL ${ }^{1}$, SOEREN TVILSTED ${ }^{2}$ and TROELS W. KJAER ${ }^{3}$ \\ ${ }^{1}$ Department of Radiation Oncology, University of Lübeck, Lübeck, Germany; \\ ${ }^{2}$ Research Projects and Clinical Optimization, Zealand University Hospital, Koege, Denmark; \\ ${ }^{3}$ Neurological Department, Zealand University Hospital, Roskilde, Denmark
}

\begin{abstract}
Background/Aim: Most patients with breast cancer are assigned to radiotherapy, which may cause fears leading to sleep disorders. Very few data are available regarding the prevalence of sleep disorders and corresponding risk factors. Patients and Methods: Data of 175 patients with breast cancer presenting for adjuvant radiotherapy were retrospectively analyzed. Twenty-three patient and tumor characteristics were investigated for associations with pre-radiotherapy sleep disorders. Results: Seventy-eight patients (44.6\%) stated sleep disorders prior to radiotherapy. These were significantly associated with higher distress score $(p<0.0001)$; greater number of emotional $(p<0.0001)$, physical $(p<0.0001)$ or practical problems $(p<0.001)$; and request for psychooncological support $(p<0.001)$. Trends were found for worse performance status $(p=0.062)$ and higher comorbidity index $(p=0.059)$. Conclusion: Sleep disorders prior to radiotherapy for breast cancer are common. This applies particularly to patients with risk factors including distress due to emotional, physical or practical problems. These patients should be offered psycho-oncological support as soon as possible.
\end{abstract}

Breast cancer is one of the most common types of solid cancer in Western countries (1). Most patients with non-metastatic breast cancer receive adjuvant local or locoregional radiotherapy, either following breast-conserving surgery or mastectomy (2). The fact that a patient needs to be irradiated may cause then fear about the unknown technology, exposure to radiation and potential side-effects of the treatment. These

This article is freely accessible online.

Correspondence to: Prof. Dirk Rades, MD, Department of Radiation Oncology, University of Lübeck, Lübeck, Ratzeburger Allee 160, 23562 Lübeck, Germany. Tel: +49 45150045401, Fax: +49 45150045404, e-mail: dirk.rades@uksh.de

Key Words: Breast cancer, radiotherapy, sleep disorders, prevalence, characteristics. fears and other factors can lead to sleep disorders. According to a previous study, sleep disorders are more common in patients with breast cancer than in those with prostate cancer (3). In another study, most sleep disorders were reported by patients to occur prior to and at the beginning of the course of radiotherapy (4). However, sleep disorders may also increase during the period of treatment as a result of acute toxicity (5). Only very few data exist regarding the prevalence of sleep disorders prior to a radiotherapy course and of potential risk factors $(6,7)$. Thus, additional studies are needed to identify and support patients suffering from stressful sleep problems. The present study was performed to determine the prevalence of sleep disorders prior to radiotherapy and to identify significant risk factors in a cohort of patients with breast cancer assigned to adjuvant radiotherapy.

\section{Patients and Methods}

A total of 175 patients with breast cancer who presented for adjuvant external beam radiotherapy and completed a National Comprehensive Cancer Network Distress Thermometer evaluation $(8,9)$ between March 2020 and February 2021 were included in this retrospective study. Patients assigned to brachytherapy or to external beam radiotherapy for a local or locoregional recurrence were not included. The study was approved by the ethics committee of the University of Lübeck (reference 21-128). After breast-conserving surgery, the patients received whole breast irradiation, either with $15 \times 2.667$ Gy over 3 weeks or $28 \times 1.8$ Gy over 6.5 weeks (2). Patients younger than 51 years and those 51 years or older with risk factors for local recurrence received a boost to the tumor bed of $5 \times 2.0$ Gy over 1 week. After mastectomy, radiotherapy of the chest wall was performed in the case of pT4 tumor, pT3 tumor plus risk factors, incomplete resection, involvement of more than three axillary lymph nodes, and involvement of one to three axillary lymph nodes plus risk factors (2). Following neoadjuvant systemic treatment and breast-conserving surgery, radiotherapy was performed in cases of cT3/cT4 tumor, ypT1 or ypN+, and after complete response to systemic treatment of $\mathrm{T} 1 / 2 \mathrm{~N}+$ tumors (2). After neoadjuvant systemic treatment followed by mastectomy, radiotherapy was administered in cases with risk factors (2). Irradiation of supra-/infraclavicular lymph nodes with or without internal mammary lymph nodes [depending on estimated heart and 
lung toxicity (10-12)] was performed in the case of involvement of more than three axillary lymph nodes and involvement of three or fewer with risk factors. When the treatment volume included lymph nodes, the preferred radiation regimen was $28 \times 1.8$ Gy (2).

The patients were evaluated for sleep disorders prior to the start of radiotherapy (no $v s$. yes) to obtain the corresponding prevalence. In addition, 23 patient and tumor characteristics were investigated for potential associations with the occurrence of sleep disorders prior to radiotherapy (Table I). These characteristics included age ( $\leq 64$ vs. $\geq 65$ years); Karnofsky performance score (90-100 vs. 60$80)$; Charlson comorbidity index (2-3 vs. $\geq 4)$; previous or concurrent additional breast cancer or ductal carcinoma in situ (DCIS) (no vs. yes); previous or concurrent additional tumor (no vs. yes); family history of malignancy in general (no $v s$. yes); family history of breast cancer or DCIS (no $v s$. yes); previous radiotherapy (no $v s$. yes); distress score $(0-4 v s . \geq 5$; median=4) according to the National Comprehensive Cancer Network Distress Thermometer (8; 9 ); number of emotional ( $0-1 v s . \geq 2$, median=1), physical ( $0-3 v s$. $\geq 4$, median $=3$ ) or practical $(0 v s . \geq 1$, median $=0)$ problems according to the Distress Thermometer; request for psycho-oncological support (no $v s$. yes); tumor type (DCIS $v s$. invasive breast cancer); type of surgery (breast conserving surgery $v s$. mastectomy); chemotherapy prior to radiotherapy (no vs. yes) and treatment volume of radiotherapy (breast/chest wall vs. breast/chest wall plus regional lymph nodes). In patients with invasive cancer, additional characteristics were investigated including primary tumor stage (T12 vs. T3-4), nodal stage (N0-1mi vs. N1-3), distant metastasis (no=M0 vs. yes=M1), histology (no special type $v s$. other histology), histological grading (1-2 vs. 3) and triple (estrogen receptor, progesterone receptor, human epidermal growth factor receptor 2 (HER2)/neu-status) negativity (no vs. yes). The statistical analyses regarding the potential associations between these characteristics and sleep disorders prior to radiotherapy were performed with the chi-square test (Fisher's exact test was used in case of $n<5$ ). $p$ Values less than 0.05 were considered as indicating significance and $p$-values under 0.07 as indicating a trend.

\section{Results}

In the entire cohort of 175 patients, 78 patients $(44.6 \%)$ stated they had a sleep disorder prior to the start of radiotherapy. Occurrence of sleep disorders was significantly associated with higher distress score $(p<0.0001)$; a greater number of emotional $(p<0.0001)$, physical $(p<0.0001)$ or practical problems $(p<0.001)$; and request for psychooncological support $(p<0.001)$. In addition, trends were found for lower Karnofsky performance score $(p=0.062)$, and higher Charlson comorbidity index $(p=0.059)$. The results of the complete analysis are summarized in Table II.

\section{Discussion}

Both non-metastatic and metastatic breast cancer are common situations in the field of radiation oncology (1318). The majority of patients with breast cancer have nonmetastatic disease and receive surgery followed by adjuvant radiotherapy (2). To be assigned to radiotherapy may cause patients certain fears that can lead to stressful sleep disorders. In the study of Garrett et al. that compared 78 patients with breast cancer to 82 with prostate cancer, the rates of fatigue $(p=0.03)$ and sleep disorders $(p<0.0001)$ were significantly higher in the breast cancer group (3). Moreover, patients with breast cancer reported significantly higher levels of fatigue $(p=0.005)$ and sleep disturbance $(p=0.008)$. However, when using wrist actigraphy, sleep quality was actually better in the breast cancer group $(p=0.02)$. Besides the type of cancer, the point in time of sleep disorders in patients receiving radiotherapy is an important issue. The study of Thomas et al. investigated changes in sleep quality in patients with breast cancer $(n=33)$ and prostate cancer $(n=23)$, during a radiotherapy course and up to 6 months afterwards (4). Patients of both groups reported that they experienced most sleep disorders prior to and at the beginning of their radiotherapy course. Coping strategies had a significant impact on sleep trajectories in both groups. Approach coping was associated with improved sleep quality in those with prostate cancer, and avoidance coping was associated with poorest sleep quality in both groups. On the contrary, in a populationbased epidemiological study including 465 patients with breast cancer and 263 with prostate cancer, insomnia increased during the course of treatment due to the sideeffects of anticancer therapy including radiotherapy (5). In general, little is known about the sleep quality of cancer patients prior to and during a course of radiotherapy.

The present study was performed to determine the prevalence of sleep disorders prior to the start of radiotherapy in a cohort of patients with breast cancer. Another major goal was the identification of significant risk factors. The prevalence of pre-radiotherapy sleep disorders was $44.6 \%$. This rate was similar to the rate of $48 \%$ found in the previous study of Savard et al. that was performed on 300 patients with non-metastatic breast cancer (6). Other previous studies observed higher rates (about 60\%) of sleep disorders in patients with breast cancer treated with radiotherapy $(19,20)$. However, these rates were assessed at 1 year following radiotherapy and not prior to or during the treatment. Therefore, these figures cannot be compared to the rates found in the study of Savard et al. (6) and in the present study. In another study that did not focus on patients with breast cancer but also included patients with prostate cancer, lung cancer and brain tumors, $57 \%$ of patients reported sleep disorders at initiation of radiotherapy (21).

In the current study, several characteristics were significantly associated or showed a trend for an association with the occurrence of sleep disorders prior to the start of radiotherapy and, therefore, can be considered risk factors. These characteristics included worse performance status, higher comorbidity index, higher distress score, request for 
Table I. Distribution of patient and tumor characteristics investigated for associations with sleep disorders prior to the start of radiotherapy in the entire cohort.

\begin{tabular}{|c|c|c|}
\hline Factor & Subgroup & Frequency, $\mathrm{n}(\%)$ \\
\hline \multirow[t]{2}{*}{ Age } & $\leq 64$ Years & $93(53.1)$ \\
\hline & $\geq 65$ Years & $82(46.9)$ \\
\hline \multirow[t]{2}{*}{ Karnofsky performance score } & $90-100$ & $143(81.7)$ \\
\hline & $60-80$ & $32(18.3)$ \\
\hline \multirow[t]{2}{*}{ Charlson comorbidity index } & $2-3$ & $149(85.1)$ \\
\hline & $\geq 4$ & $26(14.9)$ \\
\hline \multirow[t]{2}{*}{ Additional breast cancer/DCIS } & No & $161(92)$ \\
\hline & Yes & $14(8)$ \\
\hline \multirow[t]{2}{*}{ History of additional tumor } & No & $156(89.1)$ \\
\hline & Yes & $19(10.9)$ \\
\hline \multirow[t]{2}{*}{ Family history of malignancy } & No & $63(36)$ \\
\hline & Yes & $112(64)$ \\
\hline \multirow[t]{2}{*}{ Family history of breast cancer/DCIS } & No & $116(66.3)$ \\
\hline & Yes & $59(33.7)$ \\
\hline \multirow[t]{2}{*}{ Previous radiotherapy } & No & $160(91.4)$ \\
\hline & Yes & $15(8.6)$ \\
\hline \multirow[t]{2}{*}{ Distress score } & $0-4$ & $89(50.9)$ \\
\hline & $\geq 5$ & $86(49.1)$ \\
\hline \multirow[t]{2}{*}{ Number of emotional problems } & $0-1$ & $93(53.1)$ \\
\hline & $\geq 2$ & $82(46.9)$ \\
\hline \multirow[t]{2}{*}{ Number of physical problems } & $0-3$ & $96(54.9)$ \\
\hline & $\geq 4$ & $79(45.1)$ \\
\hline \multirow[t]{2}{*}{ Number of practical problems } & 0 & $131(74.9)$ \\
\hline & $\geq 1$ & $44(25.1)$ \\
\hline \multirow[t]{2}{*}{ Request for psycho-oncological support } & No & $142(81.1)$ \\
\hline & Yes & $33(18.9)$ \\
\hline \multirow[t]{2}{*}{ Tumor type } & DCIS & $17(9.7)$ \\
\hline & Invasive cancer & $158(90.3)$ \\
\hline \multirow[t]{2}{*}{ Type of surgery } & $\mathrm{BCS}$ & $154(88)$ \\
\hline & Mastectomy & $21(12)$ \\
\hline \multirow[t]{2}{*}{ Chemotherapy pre-RT } & No & $110(62.9)$ \\
\hline & Yes & $65(37.1)$ \\
\hline \multirow[t]{2}{*}{ Treatment volume of RT } & Without LN & $138(78.9)$ \\
\hline & With LN & $37(21.1)$ \\
\hline \multirow[t]{2}{*}{ Primary tumor stage* } & $\mathrm{T} 1-2$ & $142(89.9)$ \\
\hline & T3-4 & $16(10.1)$ \\
\hline \multirow[t]{2}{*}{ Nodal stage* } & N0-1 mi & $112(70.9)$ \\
\hline & $\mathrm{N} 1-3$ & $46(29.1)$ \\
\hline \multirow[t]{2}{*}{ Distant metastasis* } & No & $156(98.7)$ \\
\hline & Yes & $2(1.3)$ \\
\hline \multirow[t]{2}{*}{ Histology* } & NST & $135(85.4)$ \\
\hline & Other & $23(14.6)$ \\
\hline \multirow[t]{2}{*}{ Histologic grading* } & $1-2$ & $107(67.7)$ \\
\hline & 3 & $51(32.3)$ \\
\hline \multirow[t]{2}{*}{ Triple negative tumor* } & No & $144(91.1)$ \\
\hline & Yes & $14(8.9)$ \\
\hline
\end{tabular}

BCS: Breast-conserving surgery; DCIS: ductal carcinoma in situ; LN: lymph nodes; NST: no special type; RT: radiotherapy. *Invasive cancer only $(n=158)$.

psycho-oncological support, and greater numbers of emotional, physical or practical problems. In the study of Dhruva et al. that investigated sleep disturbance prior to, during and after radiotherapy in 73 patients with breast cancer, comorbidity, evening fatigue and depressive symptoms were associated with subjective sleep disturbance at baseline (7). In the study including different types of malignancy, mood disturbances were associated with a higher rate of sleep disorders (21). The results of our present study agree well with these findings. In addition to the previously reported characteristics, our study also identified physical and practical problems as significant risk factors for 
Table II. Associations of patient and tumor characteristics with sleep disorders prior to the start of radiotherapy.

\begin{tabular}{|c|c|c|c|c|}
\hline \multirow[b]{2}{*}{ Factor } & & \multicolumn{2}{|c|}{ Sleep disorder, $\mathrm{n}(\%)$} & \multirow[b]{2}{*}{$p$-Value } \\
\hline & & Yes & No & \\
\hline \multirow[t]{2}{*}{ Age } & $\leq 64$ Years & $43(55.1)$ & $50(51.5)$ & 0.64 \\
\hline & $\geq 65$ Years & $35(44.9)$ & $47(48.5)$ & \\
\hline \multirow[t]{2}{*}{ Karnofsky performance score } & $90-100$ & $59(75.6)$ & $84(86.6)$ & 0.062 \\
\hline & $60-80$ & $19(24.4)$ & $13(13.4)$ & \\
\hline \multirow[t]{2}{*}{ Charlson comorbidity index } & $2-3$ & $62(79.5)$ & $87(89.7)$ & 0.059 \\
\hline & $\geq 4$ & $16(20.5)$ & $10(10.3)$ & \\
\hline \multirow[t]{2}{*}{ Additional breast cancer/DCIS } & No & $69(88.5)$ & $92(94.8)$ & 0.12 \\
\hline & Yes & $9(11.5)$ & $5(5.2)$ & \\
\hline \multirow[t]{2}{*}{ History of additional tumor } & No & $72(92.3)$ & $84(86.6)$ & 0.23 \\
\hline & Yes & $6(7.7)$ & $13(13.4)$ & \\
\hline \multirow[t]{2}{*}{ Family history of malignancy } & No & $24(30.8)$ & $39(40.2)$ & 0.20 \\
\hline & Yes & $54(69.2)$ & $58(59.8)$ & \\
\hline \multirow[t]{2}{*}{ Family history of breast cancer/DCIS } & No & $51(65.4)$ & $65(67)$ & 0.82 \\
\hline & Yes & $27(34.6)$ & $32(33)$ & \\
\hline \multirow[t]{2}{*}{ Previous radiotherapy } & No & $70(89.7)$ & $90(92.8)$ & 0.48 \\
\hline & Yes & $8(10.3)$ & $7(7.2)$ & \\
\hline \multirow[t]{2}{*}{ Distress-score } & $0-4$ & $26(33.3)$ & $63(64.9)$ & $<0.0001$ \\
\hline & $\geq 5$ & $52(66.7)$ & $34(35.1)$ & \\
\hline \multirow[t]{2}{*}{ Number of emotional problems } & $0-1$ & $25(32.1)$ & $68(70.1)$ & $<0.0001$ \\
\hline & $\geq 2$ & $53(67.9)$ & $29(29.9)$ & \\
\hline \multirow[t]{2}{*}{ Number of physical problems } & $0-3$ & $21(26.9)$ & $75(77.3)$ & $<0.0001$ \\
\hline & $\geq 4$ & $57(73.1)$ & $22(22.7)$ & \\
\hline \multirow[t]{2}{*}{ Number of practical problems } & 0 & $49(62.8)$ & $82(84.5)$ & $<0.001$ \\
\hline & $\geq 1$ & $29(37.2)$ & $15(15.5)$ & \\
\hline \multirow[t]{2}{*}{ Request for psycho-oncological support } & No & $54(69.2)$ & $88(90.7)$ & $<0.001$ \\
\hline & Yes & $24(30.8)$ & $9(9.3)$ & \\
\hline \multirow[t]{2}{*}{ Tumor type } & DCIS & $4(5.1)$ & $13(13.4)$ & 0.08 \\
\hline & Invasive cancer & $74(94.9)$ & $84(86.6)$ & \\
\hline \multirow[t]{2}{*}{ Type of surgery } & $\mathrm{BCS}$ & $71(91.0)$ & $83(85.6)$ & 0.27 \\
\hline & Mastectomy & $7(9.0)$ & $14(14.4)$ & \\
\hline \multirow[t]{2}{*}{ Chemotherapy pre-RT } & No & $44(56.4)$ & $66(68.0)$ & 0.11 \\
\hline & Yes & $34(43.6)$ & $31(32.0)$ & \\
\hline \multirow[t]{2}{*}{ Treatment volume of RT } & Without LN & $60(76.9)$ & $78(80.4)$ & 0.57 \\
\hline & With LN & $18(23.1)$ & 19 (19.6) & \\
\hline \multirow[t]{2}{*}{ Primary tumor stage* } & $\mathrm{T} 1-2$ & $69(93.2)$ & $73(86.9)$ & 0.19 \\
\hline & T3-4 & $5(6.8)$ & $11(13.1)$ & \\
\hline \multirow[t]{2}{*}{ Nodal stage* } & $\mathrm{N} 0-1 \mathrm{mi}$ & $53(71.6)$ & $59(70.2)$ & 0.85 \\
\hline & $\mathrm{N} 1-3$ & $21(28.4)$ & $25(29.8)$ & \\
\hline \multirow[t]{2}{*}{ Distant metastasis* } & No & $72(97.3)$ & $84(100)$ & 0.22 \\
\hline & Yes & $2(2.7)$ & $0(0)$ & \\
\hline Histology* & NST & $67(90.5)$ & $68(81.0)$ & 0.09 \\
\hline & Other & $7(9.5)$ & $16(19.0)$ & \\
\hline Histologic grading* & G1-2 & $48(64.9)$ & $59(70.2)$ & 0.47 \\
\hline & G3 & $26(35.1)$ & $25(29.8)$ & \\
\hline Triple negative tumor* & No & $68(91.9)$ & $76(90.5)$ & 0.75 \\
\hline & Yes & $6(8.1)$ & $8(9.5)$ & \\
\hline
\end{tabular}

BCS: Breast-conserving surgery; DCIS: ductal carcinoma in situ; LN: lymph nodes; NST: no special type; RT: radiotherapy. *Invasive cancer only $(\mathrm{n}=158)$. Statistically significant $p$-Values are shown in bold.

sleep disorders. When interpreting the results of this study, its retrospective nature should be considered, which bears the risk of hidden selection biases. However, these results are important for the design of a prospective trial that will investigate sleep disorders in patients with breast cancer, prior to and during a course of radiotherapy. A particular focus of this trial will be on the impact of the use of smartphones and tablets at bedtime on sleep quality.

In conclusion, pre-treatment sleep disorders are common in patients with breast cancer assigned to radiotherapy. This 
applies particularly to patients with risk factors such as worse performance status, higher comorbidity index and distress including emotional, physical or practical problems. These patients should be offered psycho-oncological support as soon as possible, ideally during their first contact with a radiation oncologist.

\section{Conflicts of Interest}

On behalf of all Authors, the corresponding Author states that there are no conflicts of interest related to this study.

\section{Authors' Contributions}

D.R., S.T. and T.W.K. participated in the design of the study. D.R., C.A.N. and L.D. provided data. D.R. performed the analyses and interpretation of the data. D.R., S.T. and T.W.K. drafted the article, which was reviewed and finally approved by all Authors.

\section{Acknowledgements}

As part of the project NorDigHealth, this study was funded by the European Regional Development Fund through the Interreg Deutschland-Danmark program.

\section{References}

1 Siegel RL, Miller KD, Fuchs HE and Jemal A: Cancer statistics, 2021. CA Cancer J Clin 71(1): 7-33, 2021. PMID: 33433946. DOI: $10.3322 /$ caac. 21654

2 Leitlinienprogramm Onkologie (Deutsche Krebsgesellschaft, Deutsche Krebshilfe, AWMF): S3-Leitlinie Früherkennung, Diagnostik, Therapie und Nachsorge des Mammakarzinoms, Version 4.3, 2020; AWMF Registernummer: 032-045OL. Available at: https://www.awmf.org/leitlinien/detail/1l/032045OL.html [Last accessed on April 13, 2021]

3 Garrett K, Dhruva A, Koetters T, West C, Paul SM, Dunn LB, Aouizerat BE, Cooper BA, Dodd M, Lee K, Wara W, Swift P and Miaskowski C: Differences in sleep disturbance and fatigue between patients with breast and prostate cancer at the initiation of radiation therapy. J Pain Symptom Manage 42(2): 239-250, 2011 PMID: 21454042. DOI: 10.1016/j.jpainsymman.2010.11.010

4 Thomas KS, Bower J, Hoyt MA and Sepah S: Disrupted sleep in breast and prostate cancer patients undergoing radiation therapy: the role of coping processes. Psychooncology 19(7): 767-776, 2010. PMID: 19885853. DOI: 10.1002/pon.1639

5 Savard J, Ivers H, Savard MH and Morin CM: Cancer treatments and their side effects are associated with aggravation of insomnia: Results of a longitudinal study. Cancer 121(10): 17031711, 2015. PMID: 25677509. DOI: 10.1002/cncr.29244

6 Savard J, Simard S, Blanchet J, Ivers H and Morin CM: Prevalence, clinical characteristics, and risk factors for insomnia in the context of breast cancer. Sleep 24(5): 583-590, 2001. PMID: 11480655. DOI: 10.1093/sleep/24.5.583

7 Dhruva A, Paul SM, Cooper BA, Lee K, West C, Aouizerat BE, Dunn LB, Swift PS, Wara W and Miaskowski C: A longitudinal study of measures of objective and subjective sleep disturbance in patients with breast cancer before, during, and after radiation therapy. J Pain Symptom Manage 44(2): 215-228, 2012. PMID: 22795049. DOI: 10.1016/j.jpainsymman.2011.08.010

8 Holland JC, Andersen B, Breitbart WS, Buchmann LO, Compas B, Deshields TL, Dudley MM, Fleishman S, Fulcher CD, Greenberg DB, Greiner CB, Handzo GF, Hoofring L, Hoover C, Jacobsen PB, Kvale E, Levy MH, Loscalzo MJ, McAllister-Black R, Mechanic KY, Palesh O, Pazar JP, Riba MB, Roper K, Valentine AD, Wagner LI, Zevon MA, McMillian NR and Freedman-Cass DA: Distress management. J Natl Compr Canc Netw 11(2): 190209, 2013. PMID: 23411386. DOI: 10.6004/jnccn.2013.0027

9 Mehnert A, Müller D, Lehmann C and Koch U: Die deutsche version des NCCN distress-thermometers. Zeitschrift für Psychiatrie, Psychologie und Psychotherapie 54(3): 213-223, 2021. DOI: $10.1024 / 1661-4747.54 .3 .213$

10 Tuohinen SS, Skytta T, Huhtala H, Virtanen V, KellokumpuLehtinen PL and Raatikainen P: Left ventricular speckle tracking echocardiography changes among early-stage breast cancer patients three years after radiotherapy. Anticancer Res 39(8): 4227-4236, 2019. PMID: 31366510. DOI: 10.21873/anticanres. 13584

11 Gkantaifi A, Papadopoulos C, Spyropoulou D, Toumpourleka M, Iliadis G, Tsoukalas N, Kyrgias G and Tolia M: Evaluation of the irradiated volume of the heart and cardiac substructures after left breast radiotherapy. Anticancer Res 40(5): 3003-3009, 2020. PMID: 32366455. DOI: 10.21873/anticanres.14281

12 Gkantaifi A, Papadopoulos C, Spyropoulou D, Toumpourleka M, Iliadis G, Kardamakis D, Nikolaou M, Tsoukalas N, Kyrgias G and Tolia M: Breast radiotherapy and early adverse cardiac effects. the role of serum biomarkers and strain echocardiography. Anticancer Res 39(4): 1667-1673, 2019. PMID: 30952705. DOI: 10.21873/anticanres. 13272

13 Werner EM, Eggert MC, Bohnet S and Rades D: Prevalence and characteristics of pneumonitis following irradiation of breast cancer. Anticancer Res 39(11): 6355-6358, 2019. PMID: 31704867. DOI: 10.21873/anticanres. 13847

14 Janssen S, Haus R, Schild SE and Rades D: A simple clinical instrument to predict the survival probability of breast cancer patients receiving radiotherapy for bone metastases. Anticancer Res 40(1): 367-371, 2020. PMID: 31892588. DOI: 10.21873/ anticanres.13961

15 Rades D, Nguyen T, Janssen S, Khoa MT and Schild SE: Individualisation of radiation therapy for older persons with secondary brain lesions from carcinoma of the breast. Anticancer Res 40(4): 2271-2274, 2020. PMID: 32234925. DOI: 10.21873/ anticanres. 14191

16 Hansen HC, Janssen S, Thieme C, Perlov A, Schild SE and Rades D: Potential impact of the interval between imaging and whole-brain radiotherapy in patients with relatively favorable survival prognoses. Anticancer Res 39(3): 1343-1346, 2019. PMID: 30842167. DOI: 10.21873/anticanres.13247

17 Nuzzo M, Ursini LA, Patani F, Rosa C, Trignani M, DI Tommaso M, Meattini I, Gregucci F, Ciabattoni A, Genovesi D and Caravatta L: Using the bolus in post-mastectomy radiation therapy (PMRT): A national survey on behalf of the Italian Association of Radiotherapy and Clinical Oncology (AIRO) Breast Cancer Group. Anticancer Res 40(11): 6505-6511, 2020. PMID: 33109590. DOI: 10.21873/anticanres.14673

18 Lewin NL, Luetragoon T, Shamoun L, Oliva D, Andersson BÅ, Löfgren S, Rutqvist LE and Lewin F: The influence of adjuvant radiotherapy and single nucleotide polymorphisms on circulating 
immune response cell numbers and phenotypes of patients with breast cancer. Anticancer Res 39(9): 4957-4963, 2019. PMID: 31519601. DOI: 10.21873/anticanres.13684

19 Yilmaz M: Evaluation of sleep disorders in nonmetastatic breast cancer patients based on pittsburgh sleep quality index. J Cancer Res Ther 16(6): 1274-1278, 2020. PMID: 33342784. DOI: 10.4103/jcrt.JCRT_1036_19

20 Fontes F, Pereira S, Costa AR, Gonçalves M and Lunet N: The impact of breast cancer treatments on sleep quality 1 year after cancer diagnosis. Support Care Cancer 25(11): 3529-3536, 2017. PMID: 28623402. DOI: $10.1007 / \mathrm{s} 00520-017-3777-6$
21 Van Onselen C, Dunn LB, Lee K, Dodd M, Koetters T, West C, Paul SM, Aouizerat BE, Wara W, Swift P and Miaskowski C: Relationship between mood disturbance and sleep quality in oncology outpatients at the initiation of radiation therapy. Eur J Oncol Nurs 14(5): 373-379, 2010. PMID: 20080444. DOI: 10.1016/j.ejon.2009.12.002

Received March 26, 2021

Revised April 7, 2021

Accepted April 13, 2021 